\title{
The Influence of Leader-Member Communication on Organizational Commitment in a Central European Hospital
}

\author{
Valentin Kónya $^{1}$, Leposava Grubić-Nešić ${ }^{2}$, Dejan Matić ${ }^{2}$ \\ ${ }^{1}$ Faculty of Economics, University of Novi Sad \\ Segedinski put 9-11, 24000 Subotica, Serbia \\ ${ }^{2}$ Department of Industrial Engineering and Management, Faculty of Technical \\ Sciences, University of Novi Sad \\ Trg Dositeja Obradovića 6, 21000 Novi Sad, Serbia \\ valentink@uns.ac.rs,nesle@uns.ac.rs,dejan.matic@uns.ac.rs
}

\begin{abstract}
It is clear that accomplishing the goals of leadership can be easier and the process is far more successful, if both leaders and their coworkers are fully committed to their organizations, especially in stressful, demanding working environments with high levels of responsibility, such as in the health care sector. The subject of this paper is to investigate the influence of social exchange between leaders and their followers on the organizational commitment of employees. The main research question, to which this paper should give an answer, is whether social exchange between leaders and coworkers have significant influence on the organizational commitment of employees in a large hospital? The research was conducted in a Central European hospital with over 1000 employees. A total number of 359 valid questionnaires were returned. Two questionnaires were used for the research: the quality of leader-member exchange was measured with LMX-7 questionnaire for members and organizational commitment was measured with the Organizational Commitment Questionnaire - OCQ. Identical questionnaires were given to every employee included in the research, so no leader-member distinction was made among them, as the focus was on how employees as members evaluate their exchange with their leaders generally and what impact it has on their commitment. The area of interest of this research was not on specific leader-member relationships. Employees were asked to assess the quality of the exchange relationship with all of their leaders generally. The findings revealed that leader-member communication and organizational commitment have positive connectivity in a non-western environment. It was also revealed that leader-member communication and value commitment have much stronger relationship than the relationship between leader-member communication and commitment to stay.
\end{abstract}

Keywords: leader-member communication; LMX; organizational commitment; hospital; large organization; Central Europe 


\section{Introduction}

The twentieth century is characterized with evolutionary and revolutionary changes that changed the way organizations, humans and whole societies act and function. These changes led to a totally new and different approach to the functioning of organizations, in the form of leadership. The phenomenon of leadership is as old as the civilization itself and scholars around the world first started to investigate leadership or some of its forms, about 100 years ago. This means that it is certain that leadership existed since civilizations and organized groups of people emerged. The development of civilization and the society is unthinkable and could not be possible without leadership and leaders. However, scholars are showing extensive interest only in the last 100 years for researching leadership, its characteristics, dimensions and variables and for the development of modern leadership.

It has been some time since scholars and experts recognized the importance of social exchange between leaders and their coworkers in organizations. Graen and his colleagues [1-8] were among the first in research and theorization of this organizational variable, along with the influences that affects it and its outcomes. They developed, what was first known as the Vertical Dyad Linkage theory [8], which has grown to its current well-known form, the Leader-Member Exchange (LMX) theory $[9,10]$. LMX has been linked to a wide variety of organizational variables in the past, such as job satisfaction, employee performance, employee behavior and organizational commitment. Organizational commitment is a very important organizational variable, which has been investigated for half a decade, with intensification in the 70s, 80s and 90s [11, 12-17]. The main components of commitment are "strong belief in and acceptance of the organization's goals, willingness to exert considerable effort on behalf of the organization, and definite desire to maintain organizational membership" [11].

Strong leadership and organizational commitment are crucial for the effective working conditions, in which healthcare workers, save lives, every day. Foreign research have given some indications that the quality of LMX is associated with organizational commitment [18, 19-22], but there was generally not enough research and evidence to support this idea in various work conditions. Research is also needed to investigate in which ways LMX affects commitment and to what extent.

This paper departs from the general idea of the importance of strong leadership and commitment of employees in organizations, especially for those in the healthcare sector. For this purpose, research that reflects the connections between LMX and organizational commitment has been designed. A large public general hospital with over one thousand employees was chosen as the subject for this research. The managers of the hospital agreed that it is crucial to conduct research which will show to what extent, the employees are committed, to what extent leaders affect the commitment of employees and which groups of employees are critical and require immediate measures and changes. 


\section{Theoretical Background}

\subsection{Leader-Member Exchange Theory}

Leader-member exchange theory (LMX) is a relational, entity perspective approach to leadership and relationships between leaders and members with the area of interest and focus on the behaviors and properties of individuals in interactions with each other [23]. At its center is the social exchange which occurs between leaders and members [10]. According to LMX, leadership is composed of "three primary components: the characteristics of the leader; those of the follower; and the maturity of the leadership relationship" as it "occurs within the context of the leadership relationship [9]. Early LMX scholars [7, 8] argued that managers treat different subordinates differently, generally putting them into two groups, which are called 'IN' and 'OUT' groups. The members of the in-group form stronger and closer relationships with their leaders that are known as high quality exchange relationships, while members of the out-group form low quality exchange relationships with their leaders. High quality relationships are accompanied with high levels of mutual trust, respect and obligation which results in subordinate job execution beyond job descriptions and improved performance, as opposed to low quality relationships which are accompanied with low level of trust, respect and obligation and subordinate execution of only what is requested from them in job descriptions $[6,10]$. This is, in part, due to additional support, attention and information which are given to subordinates from their leaders in higher quality relationships [1]. In newer literature, "the central concept of LMX theory is that leadership occurs when leaders and followers are able to develop effective relationships that result in incremental influence and thus gain access to the many benefits these relationships bring" [23]. These effective relationships are called partnerships [10]. Graen and Uhl-Bien [9] argue that these partnerships are built through three stages in the "life cycle" of leadership. In the first "stranger" stage, the relationship and the exchange between the leader and the follower is entirely contractual with no incremental influence among them. Some relationships do not ever go beyond this stage and they stay undeveloped and of a low quality. The second "acquaintance" stage is characterized by increased, equitable, but not absolute exchange between the leader and the follower in a form of a test for advancing to the final "mature" stage of the relationship, which brings very high quality relationships-partnerships followed with loyalty, support, long time span reciprocation exchanges, emotions and high incremental influence between the leader and the follower $[9,10]$.

The origins of LMX theory lies in the VDL - Vertical Dyad Linkage theory. With VDL, differentiated dyadic relations between leaders and followers were discovered $[1,8]$. In sociology, the term 'Dyad' is used for denoting a group of two people, the smallest possible social group. 'Dyadic' is a word that is used for 
denoting interaction and communication of the mentioned groups. VDLs focus is on the reciprocal influence processes inside differentiated vertical dyads of a superior and a subordinate. It means that managers are developing differentiated relationships with direct reports, as opposed to earlier leadership approaches by which managers are using an average leadership style and develop same relationships with all of their followers [1,8]. The focus was generally on the leaders' individual behaviors. In the next stage of theory development, the focus was moved from individual behaviors to the relationships and its outcomes, which changed the focus from VDL to LMX - Leader-member exchange theory [3]. Important findings from this stage are: leaders' and followers' characteristics and behavior influence the development of the exchange relations taking place in the role creation process; high quality exchange relations have considerable positive effects for leaders, followers, departments, groups, teams and the whole organization; results of high quality exchange relations development and maintenance are also very effective leadership processes [10]. The next phase of development was on a much higher level and the traditional distinction between leaders and followers have been abandoned in favor of 'partnerships' between coworkers. Managers should make an offer to every subordinate to develop a mutual partnership among them, so every employee has equal opportunities for a high quality relationship with their manager, making the whole process of leadership more equitable. It is important that managers are encouraged to make these offers $[3,5]$. The decision on whether subordinates accept or this offer not is on them, but an equal partnership offer is crucial, because employees are well aware that if their manager treats them differently, this affects their perception of fairness [24]. Employees who accept the offer and build high quality relationships with their managers as a result have much higher performance than those subordinates who don't accept the offer $[3,5]$. Also, higher quality relationships are related to lower turnover rates and higher perceptions of leader support [2]. However, Dunegan, Uhl-Bien and Duchon [25] argue that LMX was in the past indeed connected to various organizational variables, but the proof for the links between LMX and turnover, and LMX and subordinate performance were inconsistent and required further investigation. The fourth, final phase in LMX development is turned towards "systems of interdependent dyadic relationship" [10]. A system level perspective was adopted to answer the "question of how differentiated dyadic relationships combine to form larger systems of network assemblies" [10].

\subsection{Organizational Commitment}

Organizational commitment is a work related attitude $[11,17]$. Because attitudes influence our behavior toward objects, situations, persons or groups, the most simple way to define organizational commitment is to say it is an attitude that reflects the strength of the relation between an organization and its employees [26], or the extent to which an employee is loyal to his/her organization [27]. 
Kanter [16] was one of the first do define commitment as the willingness of a social actor to give his/her energy and loyalty to a social system. In terms of organizational commitment, the term actor refers to employees and the term system refers to an organization. Porter, et al. [11] defines organizational commitment as "a strong belief in and acceptance of the organization's goals, a willingness to exert considerable effort on behalf of the organization, and a definite desire to maintain organizational membership". Similarly, Bateman and Strasser [28] discuss that commitment is defined as "multidimensional in nature, involving an employee's loyalty to the organization, willingness to exert effort on behalf of the organization, degree of goal and value congruency with the organization, and desire to maintain membership". Rusbult and Farrel [29] discuss commitment as "the likelihood that an individual will stick with a job and feel psychologically attached to it, whether it is satisfying or not". According to Agnew, et al. [30] commitment can be seen as intent to stay and endure in a relationship, including long-term navigation toward involvement and feelings of psychological attachment.

At the beginning of commitment theory and research development, it was considered as a one-dimensional variable, but later approaches recognized the need for the distinction between several types of commitment. The most recognized approach to commitment type distinction is that of Meyer and his colleagues [31, 32-34] which makes a distinction between three types of commitment: Affective, Continuance and Normative commitment in their ThreeComponent Model.

Meyer and Allen [35] argue that there can be a wide variety of factors which affect commitment development, but the strongest and most common factors are usually situational. Many researchers [15, 17, 35, 36, 37] investigated the influence of personal characteristics, mainly age, education, tenure and similar, on commitment and found connections between these two variables. According to Coe, Zehnder and Kinlaw [38] there are four critical conditions in the mind of people for building commitment in an organization: clear visions about core values and performance goals; influence over the job; competence to perform the job; and appreciation for the demonstrated performance. According to Meyer, et al. [35] age and tenure have mostly weak correlations with commitment. Further, external locus of control negatively correlates, while task self-efficacy positively correlates with affective commitment. Moral and ethics have an important influence on commitment, and this is highly expressed in public sector employees, because they have strong ethics [39].

Job characteristics and work related experiences also have a strong influence on organizational commitment [17, 35, 37]. Meyer, et al. [35] found strong correlations between work-related experiences and commitment, especially affective commitment. The investigated variables were role ambiguity, role conflict and perceived organizational support [35]. Perceived organizational support is very important for building affective commitment, by producing a felt 
obligation that helps in achieving organizational goals [40], as well as organizational dependability and trust [17]. Commitment can also be influenced by organizational changes, specifically affective commitment by changes in comfort related and competence related work experiences; continuance commitment by changes in the budget, job security and alternatives; and normative commitment by changes in the perception of the investments that the organization makes in its employees [41]. Johns and Saks [26] discuss that during recessions, a typical scenario is that employees have to stay in an organization they hate, which is related to low affective and high continuance commitment. Job security is an especially important antecedent of continuance commitment for employees in the public sector [39, 42]. Continuance commitment is also often associated with antecedents like investments and alternatives. According to Meyer and Allen [36], there can be no continuance commitment if employees don't recognize the alternatives.

Different levels of commitment can have various outcomes. Meyer, Allen and Topolnytsky [41] argue that "conditions that lead to changes in the nature of commitment can have important implications for employee morale, motivation, performance and, ultimately, organizational success". Angle and Perry [13] discuss that "a committed member's definite desire to maintain organizational membership would have a clear relationship to the motivation to participate". In their research, they also found strong evidence for the claim that there is an inverse relationship between organizational commitment and employee turnover, which was supported and proved by numerous other researches $[11,35,36,37$, 43]. Low absenteeism is also an important commitment outcome [36, 37, 43], but only for affective commitment, because continuance and normative commitment lead to higher levels of absenteeism [35]. For Steers [37], the most important outcomes of commitment are desire to remain, intent to remain, attendance, employee retention and high job performances. In their meta-analysis Meyer, et al. [35] found correlations between commitment and numerous other work related variables-consequences of commitment: negative correlation between commitment and job turnover; negative correlation between affective commitment and absenteeism; positive correlations between affective and normative commitment and job performance; negative correlation between continuance commitment and job performance; positive correlations between affective and normative commitment and organizational citizenship behavior; negative correlations between affective commitment and stress and work-family conflict; and positive correlations between continuance commitment and stress and workfamily conflict. 


\section{Method}

\subsection{Sample and Procedure}

The research was conducted in February and March 2013 in a large hospital with over 1000 employees, located in Central Europe. According to the confidentiality agreement that the authors of this paper signed with the management of the hospital, the exact name and location of the hospital cannot be revealed. A total number of 530 sets of questionnaires were distributed evenly in all departments of the hospital to all employees, without focusing on a specific type of employee except for leaders in the highest positions in hospital [management], since the research had a member focus, i.e. the interest was on the members' perceptions about the quality of the leader-member exchange relationship and its impact on their commitment. A total number of 359 valid questionnaires were returned. The return rate was $67.74 \%$. This was a very decent return rate, considering the type of activity and employees, its importance and their high level of occupancy at work. The questionnaires were completely anonymous and on every department, one person was in charge for their collection in a specially intended box. The questionnaires were all put together after the completion of the research and no distinctions were made among departments, because it was not the goal of the research.

\subsection{Description of the Sample}

The majority of the respondents were females $(77.20 \%)$; the males were in the minority (20.9\%), while only 7 employees (1.9\%) did not specify their sex. There were two significant age groups among respondents, first with the average age about 30 years and second with about 55 years as shown in Figure 1 (1.67\% did not answer this question). The arithmetic mean for age was 41.26 years (SD = 11.045). Regarding tenure with the organization, the most important group had 10 years of tenure (Figure 2), with an average of 16.33 years $(\mathrm{SD}=10.739)(3.34 \%$ left this item blank). Tenure was given only in full years, months were not taken into consideration, so 0 years in analyses refers to employees with less than a year of tenure. Since the research was conducted in the healthcare sector, with specific types of activity compared to other types of organizations, there were eight types of education offered in the questionnaires, with the results: primary school $(3.1 \%)$, secondary school $(69.9 \%)$, higher education $(9.7 \%)$, faculty-bachelor's degree $(5.8 \%)$, master's degree $(0.8 \%)$, doctors of medicine $(2.8 \%)$, specialist doctors of medicine $(7.2 \%)$ and other $(0.3 \%)$. Only one employee $(0.3 \%)$ did not provide the data for his education level. Considering that most respondents were with secondary school (nurses and administrative workers), it can be concluded that they were far more willing to complete the questionnaire than the others, since 
there is much higher percentage of medical doctors and specialists than the percentages in this research. In order for further analyses to be more concise and meaningful, respondents with higher education, faculty-bachelor's degree and master's degree were merged into a single group (with $16.3 \%$ participation in the whole sample) for further use in the analyses. Considering its irrelevance, the type "other" was excluded from further analyses.

\subsection{Instruments}

Two questionnaires were used for the research: The quality of leader-member exchange was measured with the concise LMX-7 questionnaire for members [4, 10] on a standard 5 item Likert Scale. Identical questionnaires were given to every employee included in the research, so no leader-member distinction was made among them, as the focus was on how employees as members evaluate their exchange with their leaders generally and what impact it has on their commitment, so they were all viewed as members. The area of interest of this research was not on specific leader-member relationships. Employees were asked to assess the quality of the exchange relationship with all of their leaders generally. The LMX7 is a one-dimensional scale and includes seven items with the response anchors differing with each item. This questionnaire was validated in a great number of researches [4, 10, 44-46]. It is the most accepted questionnaire for measuring LMX. Cronbach's alpha for this questionnaire in the present study was very high $(\alpha=0.93)$. The validity of the questionnaire was confirmed using principal components analysis, the statistics are relevant according to Guttman-Kaiser criterion. Considering the quantity of variance that the first component includes (70.653\% of the total variance, $\Lambda=4.946$ ), the questionnaire is one-dimensional and homogeneous. All component saturations were above 0.76. The representativeness of the items according to the KMO criterion was significant (0.923).

Organizational commitment was measured with the 15-item Organizational Commitment Questionnaire - OCQ [11], also measured on a standard 5-point Likert Scale from "completely disagree" to "completely agree". This questionnaire is the most widely used instrument for measuring organizational commitment $[14,35]$, with investigated and proven psychometric characteristics and used in measuring commitment in a wide range of job categories [12]. It includes items concerning the employee's perceptions about their loyalty to the organization, their willingness to highly engage in activities to achieve organizational aims and their acceptance of organizational values [11]. Cronbach's alpha for this questionnaire in the present study was satisfactory ( $\alpha=$ 0.881). The representativeness of the items according to the KMO criterion was significant (0.901). The validity of the questionnaire was confirmed using factor analysis, with principal components method. According to Guttman-Kaiser criterion results, two subscales were created, similar to the subscales of Angle and 
Perry [13]. The first subscale (Cronbach's alpha $=0.913, \Lambda=6.096$, includes $40.639 \%$ of the total variance) refers to the respondents value commitment, which reflects their affective commitment and includes items 1, 2, 4, 5, 6, 8, 10, 13, and 14. The second subscale (Cronbach's alpha $=0.718, \Lambda=1.883$, includes $12.550 \%$ of the total variance) refers to the respondents commitment to stay, which reflects their continuance commitment and includes items 3, 9, 11, 12, and 15. The two subscales are negatively correlated $(\mathrm{r}=-0.378)$, which reflects a weak relationship. Normative commitment was not measured in this research. In further analyses of the main scale, the items with reversed directions (items 3, 9, 11, 12 and 15) were re-coded.

\subsection{Data Processing Methods}

The data in this research was analyzed completely with the SPSS statistics software. Analyzes included descriptive statistics, instruments check (Cronbach's alpha, Guttman-Kaiser, factor analyses, representativeness, validity), analysis of the distribution of scores, descriptive statistics for scores (Mean, SD, Skewness, Kurtosis, Kolmogorov-Smirnov), correlations, ANOVA, Post-hoc test - least significant difference (LSD), Analysis of covariance (ANCOVA) and t-test.

\subsection{Research Questions and Hypotheses}

Four main research questions were created for this research:

- Does high quality exchange with leaders exist among employees of the hospital?

- Are employees of the hospital committed to the organization and its goals?

- Do personal characteristics of employees affect their LMX and commitment level?

- Does the quality of exchange with leaders influence the commitment of employees?

The hypotheses created on the basis of the research questions:

- H1: Employees of the hospital have high quality leader-member exchange relations with their leaders.

- H2: Employees of the hospital are committed to the organization.

- H3: Personal characteristics of employees influence their LMX and commitment level. 
o H3.1: Differences in gender don't affect LMX and commitment level.

o H3.2: Older and employees with longer tenure and higher education have higher levels of LMX and commitment.

- H4: The quality of the employee's LMX is correlated with their commitment levels.

o H4.1: Employees with high quality LMX are more committed to the organization's values.

\section{Results}

\subsection{Descriptive Indicators for Scores}

LMX-7 - Mean $=21.349$, SD $=6.2412$, Skewness $=-0.102$, KolmogorovSmirnov $=0.070$; according to the results, the discriminability was not significantly disrupted.

OCQ - Mean $=48.91$, SD $=10.804$, Skewness $=-0.217$, Kolmogorov-Smirnov $=$ 0.052 ; the discriminability was not disrupted significantly.

OCQ (value commitment subscale) - Mean $=30.24, \mathrm{SD}=8.169$, Skewness $=-$ 0.268 , Kolmogorov-Smirnov $=0.063$; the discriminability was not disrupted significantly.

OCQ $($ commitment to stay subscale $)-$ Mean $=17.40$, SD $=4.398$, Skewness $=$ 0.212 , Kolmogorov-Smirnov $=0.073$; the discriminability was not disrupted significantly.

\section{2 t-test for Differences}

\section{Between Genders}

The tests showed that there is statistically significant difference in organizational commitment on the whole $(\mathrm{t}=-2.131, \mathrm{p} \leq 0.05)$ and in value commitment $(\mathrm{t}=-2.699$, $\mathrm{p} \leq 0.01$ ) depending on gender. Females had higher scores on the general OCQ and the value commitment subscale. The tests did not find significant differences for LMX (Table 1). 
Table 1

t-test for differences between genders

\begin{tabular}{|c|c|c|c|c|c|c|c|c|c|}
\hline & \multicolumn{2}{|c|}{ Levene's test } & \multicolumn{7}{|c|}{$\mathrm{t}$ test for independent samples } \\
\hline & $\mathrm{F}$ & $\mathrm{p}$ & $\mathrm{t}$ & df & $\mathrm{p}$ & group & $\mathrm{N}$ & M & $\mathrm{s}$ \\
\hline \multirow{2}{*}{ LMX-7 } & \multirow[t]{2}{*}{2.358} & \multirow[t]{2}{*}{0.126} & \multirow[t]{2}{*}{-0.608} & \multirow[t]{2}{*}{342} & \multirow[t]{2}{*}{0.543} & males & 74 & 21.149 & 6.9216 \\
\hline & & & & & & females & 270 & 21.644 & 6.0031 \\
\hline \multirow{2}{*}{ OCQ } & \multirow[t]{2}{*}{0.317} & \multirow[t]{2}{*}{0.574} & \multirow[t]{2}{*}{-2.131} & \multirow[t]{2}{*}{318} & \multirow[t]{2}{*}{0.034} & males & 70 & 46.50 & 11.362 \\
\hline & & & & & & females & 250 & 49.59 & 10.533 \\
\hline \multirow{2}{*}{$\begin{array}{l}\text { Value } \\
\text { commitment } \\
\text { subscale }\end{array}$} & \multirow[t]{2}{*}{0.037} & \multirow[t]{2}{*}{0.848} & \multirow[t]{2}{*}{-2.699} & \multirow[t]{2}{*}{327} & \multirow[t]{2}{*}{0.007} & males & 72 & 28.14 & 8.411 \\
\hline & & & & & & females & 257 & 31.07 & 8.070 \\
\hline \multirow{2}{*}{$\begin{array}{l}\text { Commitment to } \\
\text { stay subscale }\end{array}$} & \multirow[t]{2}{*}{2.168} & \multirow[t]{2}{*}{0.142} & \multirow[t]{2}{*}{0.400} & \multirow[t]{2}{*}{332} & \multirow[t]{2}{*}{0.690} & males & 72 & 17.53 & 4.753 \\
\hline & & & & & & females & 262 & 17.30 & 4.203 \\
\hline
\end{tabular}

\subsection{Age and Tenure}

The relationships of age and tenure with LMX and commitment were determined with Spearman's coefficient of correlation. Negative relationships were detected between LMX and age, as well as between LMX and tenure. Older respondents and respondents with longer tenure assess the quality of exchange as lower than younger respondents and respondents with shorter tenure.

There is also negative relationship between commitment level and tenure. Employees with longer tenure are less committed to the organization. Subscale analysis revealed negative correlation between value commitment and tenure, positive correlation between commitment to stay and age, and weak positive correlation between commitment to stay and tenure (Table 2).

Table 2

Spearman's coefficients of correlation

\begin{tabular}{|c|c|c|c|}
\hline & & Age & Tenure \\
\hline \multirow[t]{3}{*}{ LMX-7 } & Spearman $\rho$ & $-.134^{*}$ & $-.190^{* * *}$ \\
\hline & $\mathrm{p}$ (2-tailed) & 0.012 & 0.000 \\
\hline & $\mathrm{N}$ & 346 & 340 \\
\hline \multirow[t]{3}{*}{ OCQ } & Spearman $\rho$ & -0.044 & $-0.119^{*}$ \\
\hline & $\mathrm{p}$ (2-tailed) & 0.428 & 0.035 \\
\hline & $\mathrm{N}$ & 322 & 317 \\
\hline \multirow{3}{*}{$\begin{array}{ll}\text { Value } & \text { commitment } \\
\text { subscale } & \end{array}$} & Spearman $\rho$ & 0.006 & -0.093 \\
\hline & $\mathrm{p}$ (2-tailed) & 0.914 & 0.095 \\
\hline & $\mathrm{N}$ & 332 & 326 \\
\hline \multirow{3}{*}{$\begin{array}{l}\text { Commitment to stay } \\
\text { subscale }\end{array}$} & Spearman $\rho$ & 0.105 & 0.085 \\
\hline & $\mathrm{p}$ (2-tailed) & 0.054 & 0.122 \\
\hline & $\mathrm{N}$ & 335 & 330 \\
\hline
\end{tabular}




\subsection{Education Level}

The ANOVA test noticed statistically significant differences among subgroups of respondents with different education levels in LMX evaluation $(\mathrm{F}(4 ; 344)=$ $3.058, \mathrm{p} \leq 0.05)$. The LSD test showed that respondents with primary education and doctors of medicine more positively evaluate their exchange with leaders compared to other employees. However, LSD is very liberal and typically has a high Type I error rate.

In evaluating their commitment level, the ANOVA test noticed statistically marginal differences among subgroups of respondents with different education levels $(\mathrm{F}(4 ; 320)=2.200, \mathrm{p}=0.07)$. The LSD test showed that doctors of medicine more positively evaluate their organizational commitment compared to respondents with high school, bachelor's and master's degrees and specialist doctors of medicine.

Value commitment subscale ANOVA analysis revealed statistically significant differences among subgroups of respondents with different education levels ( F (4; $329)=2.541, \mathrm{p} \leq 0.05)$. The LSD test showed that respondents with primary education and doctors of medicine are more committed to the values of the organization than other respondents.

Commitment to stay subscale ANOVA analysis did not reveal any statistically significant differences among subgroups of respondents with different education levels $(\mathrm{F}(4 ; 334)=1.927, \mathrm{p}=0.11)$.

\subsection{Pearson Correlations between LMX and Organizational Commitment}

There are significant connectivity between LMX and organizational commitment evaluation $(\mathrm{r}=0.539, \mathrm{p} \leq 0.01), \mathrm{LMX}$ and value commitment subscale $(\mathrm{r}=0.553$, $\mathrm{p} \leq 0.01$ ), and negative connectivity between LMX and commitment to stay subscale $(\mathrm{r}=-0.311, \mathrm{p} \leq 0.01)$.

Table 3

Pearson's correlations between concepts

\begin{tabular}{|r|l|r|r|r|}
\hline \multicolumn{2}{|c|}{} & $\begin{array}{c}\text { Organizational } \\
\text { commitment }\end{array}$ & $\begin{array}{c}\text { Value commitment } \\
\text { subscale }\end{array}$ & $\begin{array}{c}\text { Commitment to } \\
\text { stay subscale }\end{array}$ \\
\hline \multirow{3}{*}{ LMX } & Pearson Correlation & $0.539^{* *}$ & $0.553^{* *}$ & $-0.311^{* *}$ \\
\cline { 2 - 5 } & $\mathrm{p}$ (2-tailed) & 0.000 & 0.000 & 0.000 \\
\cline { 2 - 5 } & $\mathrm{N}$ & 321 & 330 & 335 \\
\hline
\end{tabular}




\subsection{ANCOVA}

In order to get more accurate and useful results, respondents with primary and high school education were merged into one group in this test. Levene's test for equality of error variances showed that the variance is homogeneous, which is a requirement for this analysis. LMX, age, tenure, gender and education were used as predictors, while organizational commitment was used as the criterion (dependent) variable.

Covariance analysis showed that predictors LMX and gender had significant effect on organizational commitment $(\mathrm{LMX}:(\mathrm{F}(1 ; 301)=114.582, \mathrm{p} \leq 0.01$, Partial $\eta 2=0.276)$, gender: $(F(1 ; 301)=5.587, p \leq 0.05$, Partial $\eta 2=0.018))$. The corrected value of squared multiple correlation shows that $29 \%$ of the total variance of the criterion variable are explained with this set of predictors.

Respondents that positively evaluate the quality of LMX also positively evaluate their organizational commitment $(b=0.909, p \leq 0.01$, Partial $\eta 2=0.276)$. Females are more committed to the organization in general $(b=-6.738, p=0.08$, Partial $\eta 2=0.010$ ). Doctors of medicine and specialist doctors of medicine are also more committed to the organization compared to other respondents, although the effects of education do not have high significance.

Table 4

Tests of Between-Subjects Effects

\begin{tabular}{|c|c|c|c|c|c|c|}
\hline Source & $\begin{array}{c}\text { Type III Sum of } \\
\text { Squares }\end{array}$ & df & $\begin{array}{l}\text { Mean } \\
\text { Square }\end{array}$ & $\mathrm{F}$ & Sig. & $\begin{array}{c}\text { Partial } \\
\eta^{2}\end{array}$ \\
\hline Corrected Model & $11153.540^{\mathrm{a}}$ & 9 & 1239.282 & 15.301 & 0.000 & 0.314 \\
\hline Intercept & 7273.178 & 1 & 7273.178 & 89.800 & 0.000 & 0.230 \\
\hline LMX & 9280.356 & 1 & 9280.356 & 114.582 & 0.000 & 0.276 \\
\hline Age & 66.305 & 1 & 66.305 & 0.819 & 0.366 & 0.003 \\
\hline Gender & 452.537 & 1 & 452.537 & 5.587 & 0.019 & 0.018 \\
\hline el & 491.278 & 3 & 163.759 & 2.022 & 0.111 & 0.020 \\
\hline Gender * el & 119.362 & 3 & 39.787 & 0.491 & 0.689 & 0.005 \\
\hline Error & 24378.833 & 301 & 80.993 & & & \\
\hline Total & 773352.000 & 311 & & & & \\
\hline Corrected Total & 35532.373 & 310 & & & & \\
\hline
\end{tabular}




\section{Discussions}

Some scholars already emphasized the important connections between LMX and organizational commitment [18, 19-22]. However, most researches do not reveal anything deeper than the simple notation that LMX correlates with organizational commitment. For example, Gerstner and Day [22] conclude that LMX is consistently correlated with commitment, but they don't reveal anything significant about the nature of this relationship. Some of the researchers, who have previously conducted similar studies $[19,20]$ also noted that it is difficult to find research that incorporates LMX as an antecedent of commitment and that only a few studies deal with this issue. Joo [20] tried to go deeper in explaining the relationship between these two variables, however he measured only affective commitment and provided only the basic analysis and just discussed that LMX is indeed related and has impact on commitment. Kang and his colleagues [19] made an interesting observation in favor of the necessity to conduct research on the impact of LMX on organizational commitment in various working environments that most of the researches incorporating LMX and commitment have been conducted in western developed economies. It also seems that in the majority of these researches LMX as an antecedent of organizational commitment, analysis of their relationship and their importance are lost in the chaos between many other variables measured in these sometimes over complicated studies. Another problem is that these studies often use different instruments for measuring both LMX and commitment, so the findings cannot be homogenous and completely comparable. In some researches, LMX is only used as a mediator variable [21].

This study intended to contribute in solving at least two main issues noticed, the necessity to conduct researches outside western settings, and the unnecessary complication of studies incorporating LMX and commitment. It also had the intention to go further and deeper in explaining the relationships of these variables.

\subsection{Discussion of the Results}

H1, which proposes that employees have high quality LMX with their leaders, was partially supported with descriptive statistics. H2, proposing that employees are committed to the organization, also received partial support. The analyses showed that there is much empty space for improving the employees LMX and commitment. Personal characteristics have significant influence on both of the variables tested. Therefore, H3, suggesting that personal characteristics of employees influences their LMX and commitment level, received full support. Females are more committed to the organization and to its values. It is known that females are typically drawn to the healthcare sector because of their nurturing attitudes. LMX was not affected by gender, so H3.1, proposing that differences in gender do not affect LMX and commitment level was supported only for LMX. 
Age, tenure and education analyses revealed very unexpected results. Regarding age differences and tenure, analysis showed that older respondents and those with longer tenure have lower LMX. Respondents with longer tenure are also less committed to the organization generally and to its values, while their commitment to stay increases with age and tenure. The presumption is that older and employees with longer tenure are more objective in evaluating their LMX and commitment. As time passes, they are more informed about the reality. The shock of facing the reality can have significant impact on people. The results can be perceived through the self-determination theory, which points on the autonomous behavior regulation style through the integration of life experience and personality disposition in a unique system of the self $[47,48]$. They also realize that as they get older that finding another job will get harder, so the job security granted to them as to most public service organization employees leads to higher commitment to stay. Higher LMX and value commitment had respondents with primary education and doctors of medicine than others, while doctors of medicine are generally most committed to the organization. The ANCOVA test added specialist doctors of medicine to the list of generally most committed, but with small significance. High levels of LMX and commitment among employees with only primary education was indeed a surprise. As age, tenure and education do not influence LMX and commitment in the expected way, H3.2 is not supported.

The most important analysis in this study is the correlation analysis between LMX and commitment. The tests confirmed the results of many earlier studies [18, 1922] that LMX and commitment are significantly positively correlated. Further, analysis revealed that respondents with high quality LMX are more committed to the organization's values [positive correlation] and have lower level of commitment to stay [negative correlation]. Employees with higher LMX are more likely to engage themselves in achieving the values of the organization, however they leave easier from the organization, which reflects affective commitment towards the organization. The ANCOVA test also confirmed the connection between LMX and commitment and revealed that $29 \%$ of the total variance of organizational commitment is explained with predictors LMX and age. Thus, H4, proposing that LMX correlates commitment is supported with high certainty. $\mathrm{H} 4.1$, proposing that employees with high LMX have higher value commitment, is also supported with great confidence.

\section{Conclusions}

Different economic and cultural conditions can reveal different facts about the nature of important organizational variables, in this case, concerning the exchange between leaders and members, and organizational commitment. As mentioned before, most of the studies conducted on both LMX and organizational commitment were in Western environments. Thus, non-western environments had little influence on the theory and practice development. Therefore, sometimes the theory does not correspond to the characteristics of these cultural and business environments. 
The main findings in this study revealed that LMX and organizational commitment have positive connectivity in a non-western environment. It was also revealed that LMX and value commitment have much stronger relationship than the relationship between LMX and commitment to stay, which is a negative relationship. Critical employee categories were also detected. Measures for improving their LMX and commitment are needed primarily for males, older employees, employees with longer tenure and employees with secondary education, bachelor's and master's degrees. The conclusion is that leaders and leadership have strong influence on the commitment of their employees, so these findings could have significant implications in the process of leadership modernization in stressful and demanding working environments. Knowing how important commitment can be among healthcare workers, greater attention needs to be given to leadership in hospitals.

Further research is needed and data should be collected from many different environments, in the region, to learn more about the influence of LMX on organizational commitment. According to Perry [39], moral and ethics have an important influence on commitment, and this is highly expressed among public sector employees, because they have strong ethics. It would be interesting to incorporate moral and ethics, as moderator variables, in further studies examining the influence of LMX on organizational commitment.

\section{Acknowledgement}

The authors wish to thank the reviewers for their constructive comments that were very helpful in improving the quality of this paper.

The work on this paper was supported by the Provincial Secretariat for Science and Technological Development of the Autonomous Province of Vojvodina, through the project "Effects of Organizational Communication on Organizational Behavior of Employees"

\section{References}

[1] G. Graen, J. Cashman: A Role-Making Model of Leadership in Formal Organizations: A Developmental Approach. In J. G. Hunt, L. L. Larson (eds.): Leadership Frontiers, Kent State University Press, Kent, 1975, pp. $143-166$

[2] G. Graen, W. Hoel, R. C. Liden: Role of Leadership in the Employee Withdrawal Process, Journal of Applied Psychology, 67, 6, 1982, pp. 868872

[3] G. Graen, M. A. Novak, P. Sommerkamp: The Effects of Leader-Member Exchange and Job Design on Productivity and Satisfaction: Testing a Dual Attachment Model, Organizational Behavior and Human Performance, 30, 1, 1982, pp. 109-131 
[4] T. A. Scandura, G. Graen: Moderating Effects of Initial Leader-Member Exchange Status on the Effects of a Leadership, Journal of Applied Psychology, 69, 3, 1984, pp. 428-436

[5] G. Graen, T. A. Scandura, M. R. Graen: A Field Experimental Test of the Moderating Effects of Growth Need Strength on Productivity, Journal of Applied Psychology, 71, 3, 1986, pp. 484-91

[6] M. D. Zalesny, G. Graen: Exchange Theory in Leadership Research. In: Reber G, editor. Encyclopedia of Leadership, Linz University Press, Linz, 1986

[7] G. Graen, T. A. Scandura: Toward a Psychology of Dyadic Organizing. In B. M. Staw, L. L. Cummings (eds.): Research in Organizational Behavior, JAI Press, Greenwich, 1987, pp. 175-208

[8] F. Dansereau Jr., G. Graen, W. J. Haga: A Vertical Dyad Linkage Approach to Leadership within Formal Organizations: A Longitudinal Investigation of the Role Making Process, Organizational Behavior and Human Performance, 13, 1, 1975, pp. 46-78

[9] G. Graen, M. Uhl-Bien: The Transformation of Work Group Professionals into Self-Managing and Partially Self-Designing Contributors: Toward a Theory of Leadership-Making, Journal of Management Systems, 3, 3, 1991, pp. 25-39

[10] G. Graen, M. Uhl-Bien: Relationship-based Approach to Leadership: Development of Leader-Member Exchange (LMX) Theory of Leadership over 25 Years: Applying a Multi-Level Multi-Domain Perspective, The Leadership Quarterly, 6, 2, 1995, pp. 219-247

[11] L. W. Porter, R. M. Steers, R. T. Mowday, P. V. Boulian: Organizational Commitment, Job Satisfaction, and Turnover among Psychiatric Technicians, Journal of Applied Psychology, 59, 5, 1974, pp. 603-609

[12] R. T. Mowday, R. M. Steers, L. W. Porter: The Measurement of Organizational Commitment, Journal of Vocational Behavior, 14, 2, 1979, pp. 224-247

[13] H. L. Angle, J. L. Perry: An Empirical Assessment of Organizational Commitment and Organizational Effectiveness, Administrative Science Quarterly, 26, 1, 1981, pp. 1-14

[14] J. P. Meyer, N. J. Allen: Testing the 'Side-Bet Theory' of Organizational Commitment: Some Methodological Considerations, Journal of Applied Psychology, 69, 3, 1984, pp. 372-378

[15] J. P. Meyer, N. J. Allen, C. A. Smith: Commitment to Organizations and Occupations: Extension and Test of a Three-Component Conceptualization, Journal of Applied Psychology, 78, 4, 1993, pp. 538-551 
[16] R. M. Kanter: Commitment and Social Organization: A Study of Commitment Mechanisms in Utopian Communities, American Sociological Review, 33, 4, 1968, pp. 499-517

[17] B. Buchanan: Building Organizational Commitment: The Socialization of Managers in Work Organizations, Administrative Science Quarterly, 19, 4, 1974, pp. 533-546

[18] A. Yousaf, K. Sanders, N. Torka, J. Ardts: Having Two Bosses: Considering the Relationships between LMX, Satisfaction with HR Practices, and Organizational Commitment, International Journal of Human Resource Management, 22, 15, 2011, pp. 3109-3126

[19] D. S. Kang, J. Stewart, H. Kim: The Effects of Perceived External Prestige, Ethical Organizational Climate, and Leader-Member Exchange (LMX) Quality on Employees' Commitments and their Subsequent Attitudes, Personnel Review, 40, 6, 2011, pp. 761-784

[20] B. K. Joo: Organizational Commitment for Knowledge Workers: The Roles of Perceived Organizational Learning Culture, Leader-Member Exchange Quality, and Turnover Intention, Human Resource Development Quarterly, 21, 1, 2010, pp. 69-85

[21] J. Lee: Effects of Leadership and Leader-Member Exchange on Commitment, Leadership and Organization Development Journal, 26, 7/8, 2005, pp. 655-672

[22] C. R. Gerstner, D. V. Day: Meta-Analytic Review of Leader-Member Exchange Theory: Correlates and Construct Issues, Journal of Applied Psychology, 82, 6, 1997, pp. 827-844

[23] M. Uhl-Bien: Relational Leadership Theory: Exploring the Social Processes of Leadership and Organizing, Leadership Quarterly, 17, 6, 2006, pp. 654-676

[24] P. M. Sias, F. M. Jablin: Differential Superior-Subordinate Relations, Perceptions of Fairness, and Coworker Communication, Human Communication Research, 22, 1, 1995, pp. 5-38

[25] K. J. Dunegan, M. Uhl-Bien, D. Duchon: LMX and Subordinate Performance: The Moderating Effects of Task Characteristics, Journal of Business and Psychology, 17, 2, 2002, pp. 275-285

[26] G. Johns, A. M. Saks: Organizational Behaviour: Understanding and Managing Life at Work, Pearson Prentice Hall, 2005

[27] J. R. Schermerhorn, J. G. Hunt, R. N. Osborn, M. Uhl-Bien: Organizational Behavior, John Wiley \& Sons, 2010

[28] T. S. Bateman, A. Strasser: A Longitudinal Analysis of the Antecedents of Organizational Commitment, The Academy of Management Journal, 27, 1, 1984, pp. 95-112 
[29] C. E. Rusbult, D. Farrell: A Longitudinal Test of the Investment Model: The Impact on Job Satisfaction, Job Commitment, and Turnover of Variations in Rewards, Costs, Alternatives, and Investments, Journal of Applied Psychology, 68, 3, 1983, pp. 429-438

[30] C. R. Agnew, P. A. M. Van Lange, C. E. Rusbult, C. A. Langston: Cognitive Interdependence: Commitment and the Mental Representation of Close Relationships, Journal of Personality and Social Psychology, 74, 4, 1998, pp. 939-954

[31] N. J. Allen, J. P. Meyer: The Measurement and Antecedents of Affective, Continuance and Normative Commitment to the Organization, Journal of Occupational Psychology, 63, 1990, pp. 1-18

[32] N. J. Allen, J. P. Meyer: Affective, Continuance, and Normative Commitment to the Organization: An Examination of Construct Validity, Journal of Vocational Behavior, 49, 3, 1996, pp. 252-276.

[33] J. P. Meyer, D. J. Stanley, T. A. Jackson, K. J. McInnis, E. R. Maltin, L. Sheppard: Affective, Normative, and Continuance Commitment Levels across Cultures: A Meta-Analysis, Journal of Vocational Behavior, 80, 2, 2012, pp. 225-245

[34] J. P. Meyer, N. J. Allen: A three-Component Conceptualization of Organizational Commitment, Human Resource Management Review, 1, 1991, pp. 61-89

[35] J. P. Meyer, N. J. Allen: Commitment in the Workplace: Theory, Research, and Application, SAGE, Thousand Oaks, 1997

[36] J. P. Meyer, D. J. Stanley, L. Herscovitch, L. Topolnytsky: Affective, Continuance, and Normative Commitment to the Organization: A MetaAnalysis of Antecedents, Correlates, and Consequences, Journal of Vocational Behavior, 61, 1, 2002, pp. 20-52

[37] R. M. Steers: Antecedents and Outcomes of Organizational Commitment, Administrative Science Quarterly, 22, 1, 1977, pp. 46-56

[38] C. Coe, A. Zehnder, D. C. Kinlaw: Coaching for Commitment: Achieving Superior Performance from Individuals and Teams, John Wiley \& Sons, 2008

[39] J. L. Perry: Antecedents of Public Service Motivation, Journal of Public Administration Research and Theory, 7, 2, 1997, pp. 181-197

[40] L. Rhoades, R. Eisenberger: Perceived Organizational Support: A Review of the Literature, Journal of Applied Psychology, 87, 4, 2002, pp. 698-714

[41] J. P. Meyer, N. J. Allen, L. Topolnytsky: Commitment in a Changing World of Work, Canadian Psychology-Psychologie Canadienne, 39, 1/2, 1998, pp. 83-93 
[42] J. L. Perry, J. L. Brudney, D. Coursey, L. Littlepage: What Drives Morally Committed Citizens? A Study of the Antecedents of Public Service Motivation, Public Administration Review, 68, 3, 2008, pp. 445-458

[43] C. Ostroff: The Relationship between Satisfaction, Attitudes, and Performance: An Organizational Level Analysis, Journal of Applied Psychology, 77, 6, 1992, pp. 963-974

[44] J. M. Maslyn, M. Uhl-Bien: Leader-Member Exchange and Its Dimension: Effects of Self-Effort and Other's Effort on Relationship Quality, Journal of Applied Psychology, 86, 4, 2001, pp. 697-708

[45] G. J. Greguras, J. M. Ford: An Examination of the Multidimensionality of Supervisor and Subordinate Perceptions of Leader-Member Exchange, Journal of Occupational and Organizational Psychology, 79, 2006, pp. 433465

[46] J. A. Zhong, W. Lam, Z. G. Chen: Relationship between Leader-Member Exchange and Organizational Citizenship Behaviors: Examining the Moderating Role of Empowerment, Asia Pacific Journal of Management, 28, 3, 2011, pp. 609-626

[47] E. L. Deci, R. M. Ryan: Self-Determination Theory: A Macrotheory of Human Motivation, Development, and Health, Canadian PsychologyPsychologie canadienne, 49, 3, 2008, pp. 182-185

[48] C. F. Lam, S. T. Gurland: Self-determined Work Motivation Predicts Job Outcomes, but What Predicts Self-determined Work Motivation?, Journal of Research in Personality, 42, 4, 2008, pp. 1109-1115 